\title{
العلاقة بين إدارة علاقات العملاء وقيمة فترة حياة العميل \\ " دراسة تطبيقية "
}

\author{
أ.د. عبد القادر محمد عبد القادر \\ أستاذ الإدارة والتسويق \\ عميا الكلية الاسبق \\ كلية التجارة -جامعة المنصورة \\ الباحثه \\ أسماء البيلى النجار
}

الملخص:

تهاف الاراسة الحالية إلى معرفة العلاقه بين إدارة علاقات العملاء والثولاء وذلك بالتطبيق علي عملاء

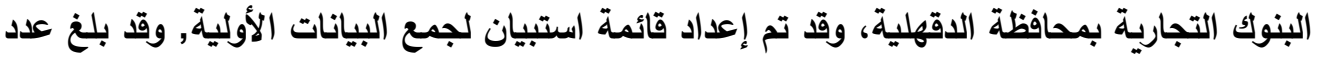

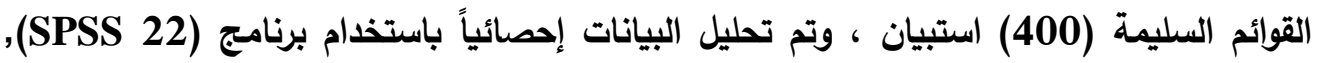

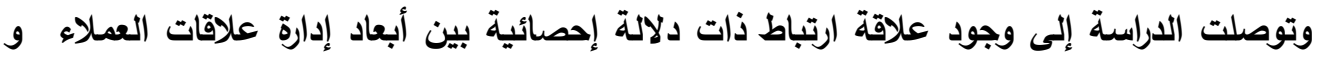

$$
\text { كلمات مفتاحية ( إدارة علاقات العملاء , الولاء ) }
$$

\section{Abstract:}

The present study aimed to investigate the relationship between customer relationship management and the customer Loyalty in commercial bank customers in Dakahlia Governorate, Data were collected from 400 questionnaires and analyzed statistically using the SPSS 22 program. The findings of the study indicate that there is a significant correlation between the dimensions of customer relationship management and the customer Loyalty.

Keywords: Customer Relationship Management - Customer Loyalty 


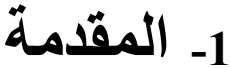

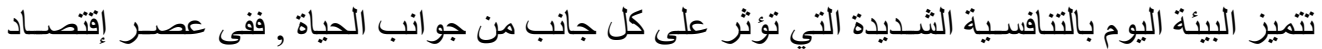

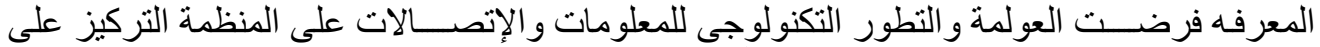

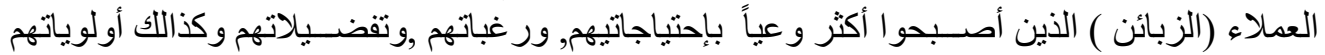
(Ngambi and Ndifor ,2015) وبالتالي تعتبر إدارة علاقات العملاء (CRM) Customer Relationship Management) مهمة

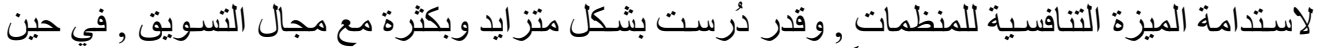

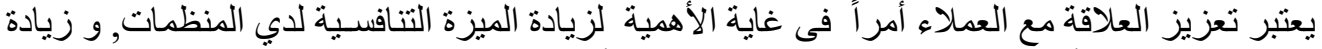

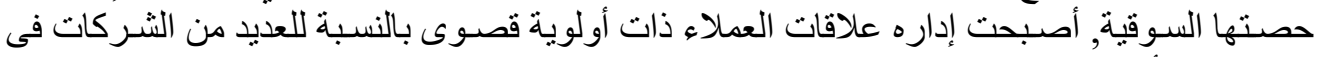

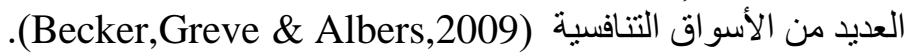

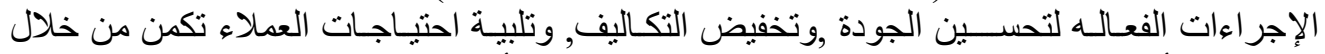

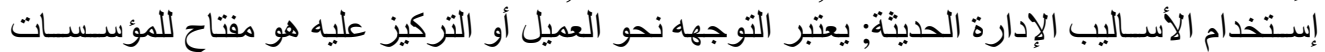

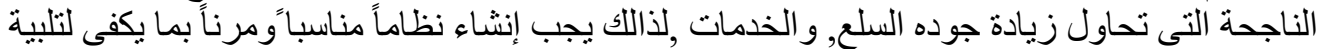

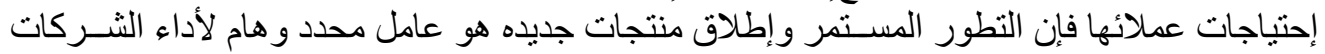
المستدامة (Sorescu and Spanjol,2008).

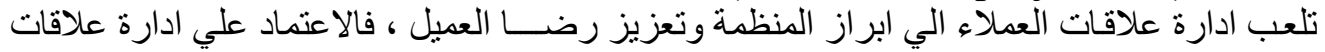

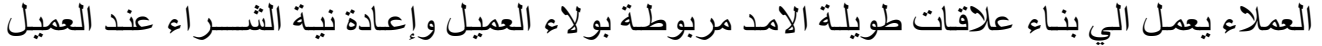

(ER,2020)

هدف التســويق هو بنـاء علاقات طويلـة الأمد و موثوق فيها, ومفيدة للطرفين مع العملاء ذو القيمـة (kim \&Cha,2002)

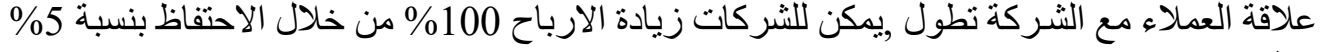
فقط من عملائها (Reichheld and Sasser,1990).

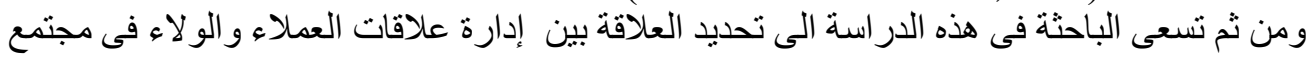

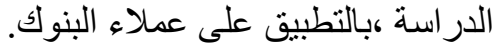
وبناء علية ، يكمن سؤال البحث فيماء يلي :ما تأثثر إدارة علاقات العملاء علي الولاء

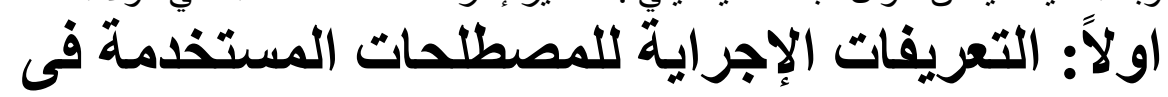

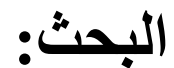
المتغير الاول: إدارة علاقات العملاء CUSTOMER RELATIONSHIP ( CRM) MANAGEMENT 1 - 1 - مفهوم إدارة علاقات العملاء:

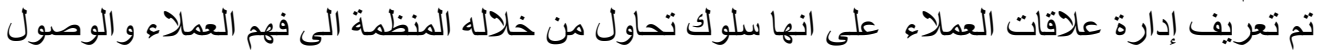

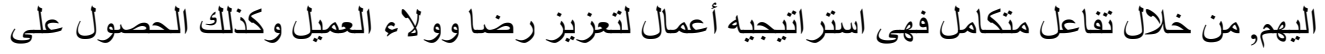

الارباح (Swift,2001). 
2- - 2 أبعاد إدارة علاقات العملاء:

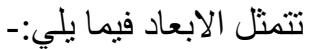

1- قنوات خدمية أكثر تنوع (MORE DIVERSIFIED SERVICE CHANNELS)

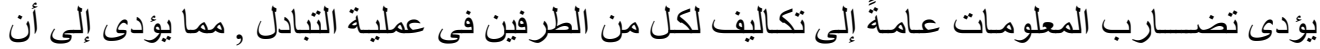

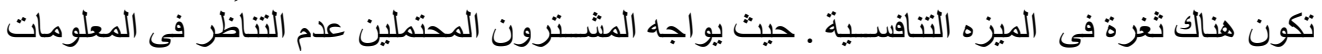

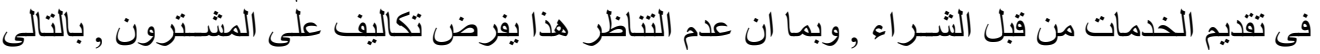

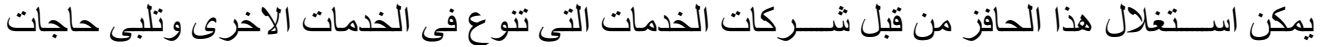
العملاء الحاليين و المرتقبين (Nayyer\& Safavi-Naini,1990). 2- الثقة فى الخدمات (TRUST IN SERVICE) تتر اكم المعرفة من ملاحظة سلوك العميل داخل

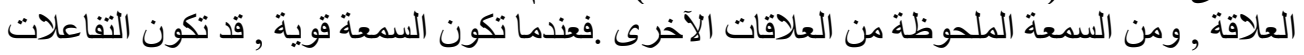

الاولية مجرد فرص للتأكد او عدم التأكد للتصور ات السات السابقة (Johnson \& Grayson,2005). 3- إنخفاض التكلفة ( LOW SERVICE COST) يعتبر إنخفاض التكاليف هى تكيف مع الوضع (U) التنافسى المنطور (O’Connell \& Connolly, 2017). التى تركز إستر اتيجياتها على التمايز أو الإستر اتيجيات منخفضة التكاليف تتمتع بميزة تنافسة ـ تقداف

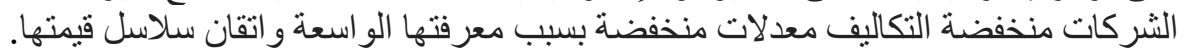

4- ن حماية الخصوصية (PRIVACY PROTECTION)

تختلف تعريفات الخصوصية إعتماداً على الإعدادات و العو امل البيئية . خاصة في سياق إدارة علاقات

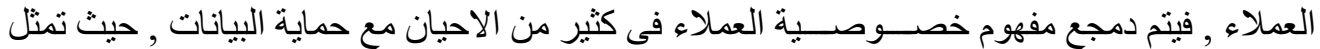

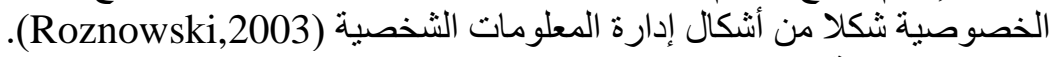

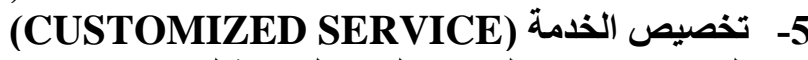

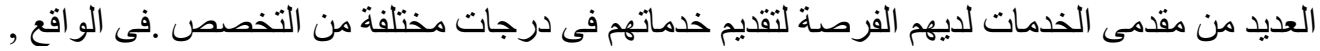

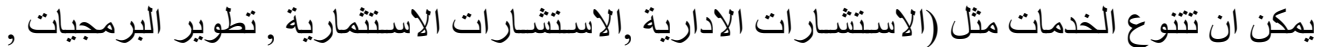

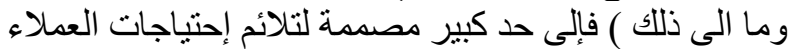

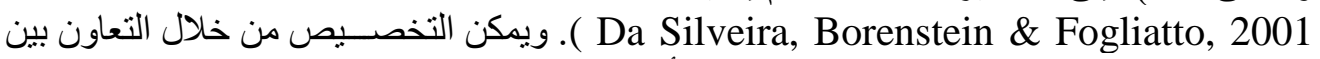

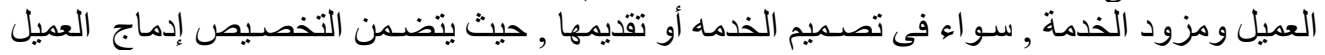

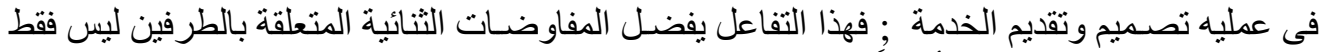
بتكوين حزمة الخدمات ولكن أيضاً بالسعر النهائى (Roth, Woratschek \& Pastowski 2006)

6- سهوله الوصل للخدمات ) EASY ACCESS TO SERVICES)

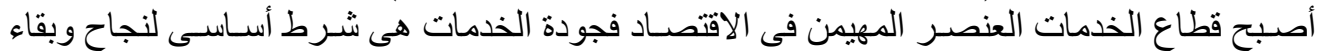

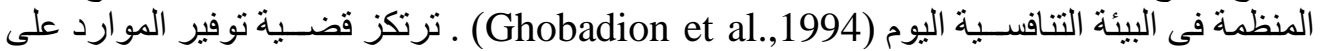

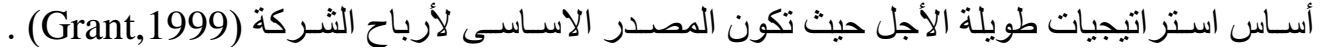

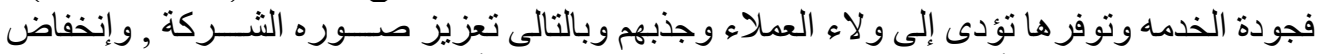

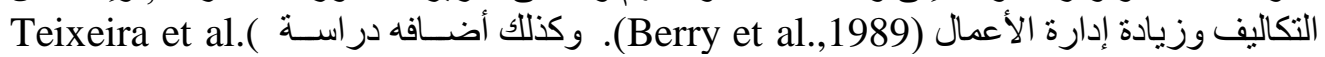

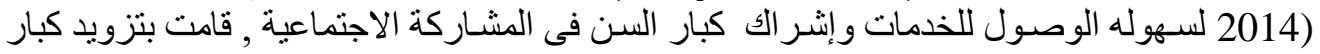




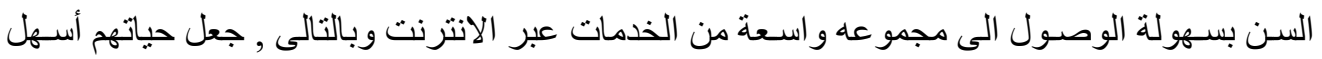

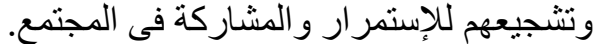

7- الوصول السريع للخدمات (QUICK ACCESS TO SERVICES)

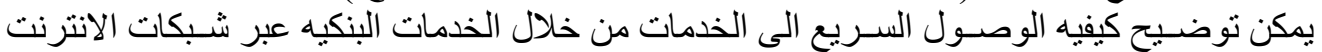
حتى تكون القدرة للوصـول الى أمو الهم فى أى مكان وفى الوفى أى وقت (Rutecka \& Bednarz,2017)

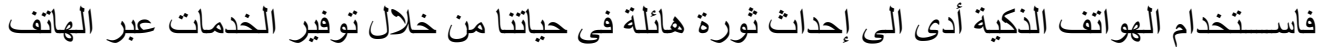

المحمول , وكذلك سهولة الوصول السريع للخدمات و السر عة و الر احة (Moloo et al.,2010).

8- ساعات خدمية طويلة (EXTENDEB SERVICE HOURS)

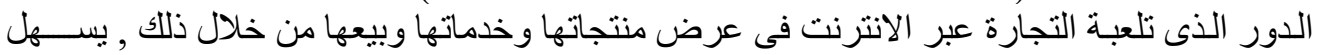

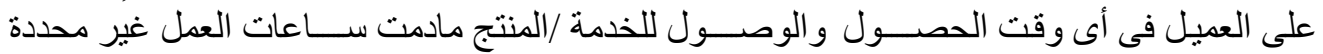

.(Keeney,1999)

LOYALTY المتغير الثاني: ولاء العميل CUSTOMER

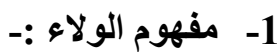

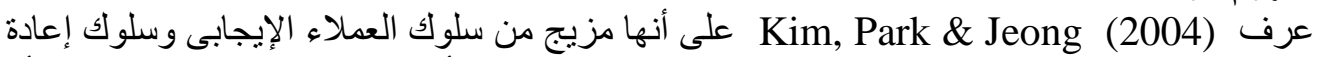

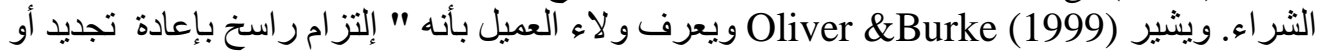

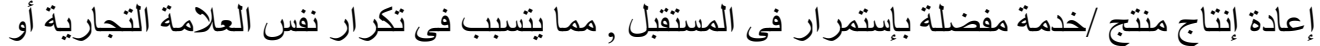

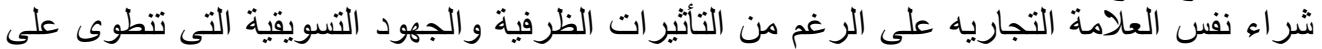

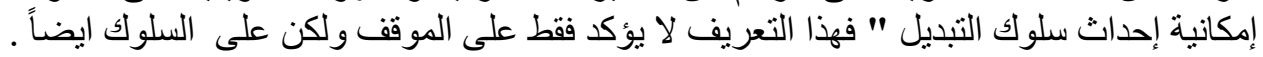

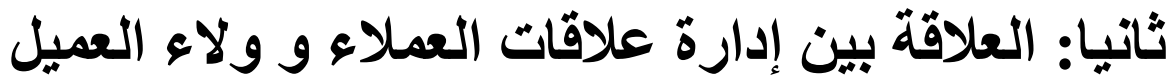

يمكن للسلوكيات الموجهه نحو العملاء أن تحافظ على قوه العلاقة بين المتلقى ومقدم الخدمه, مما يؤدى إلى تحسين أداء المنظمه , فإن أحد الأهداف الهامه للسلوكيات الموجهه نحو العميل زيادة الرضا على المدى الطويل وكذلك خلق ولاء للعميل (Brow et al.,2002). يمكن فهم دورة حياه العميل على أنها سلسلة من المعاملات بين الشركة و عملائها , طول الفترة الزمنية التى يظل خلالها العميل فى تعاملة مع الشركة .فى عام2008 خضعت إدارة علاقات العملاء لتحول كبير من el at., 2017 ( استراتيجية ركزت فقط على معامله العملاء الى استراتيجية تدمج تفاعلات العملاء عهدهية

.( Shokohyar اشارة نتائج دراسة.(Turulja \& Činjarević,2021) ان إدارة علاقات العملاء الإلكترونية لها تأثثر إجابي غير مباشر علي ولاء العميل من خلال جودة الخدمة. فى حين أوضحت دراسة 
(Elfving \& Lemoine,2012)

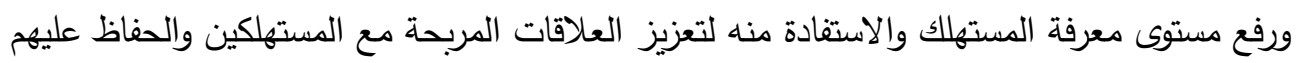
وتعزيز ولائهم علي المدي البعيد .

كما اوضحت دراسة (2007 (Oly Ndubisi el at. علاقة اداره علاقات العملاء بأسس تسويق العلاقات (الالتزام - مهارات التواصل - مهارات التعامل مع النزاعات) من ناحيه ولاء العميل والحفاظ علية , واضحت النتائج استراتيجيات تسويق العلاقات لها تاثير مباشر وغير مباشر على ولاء العميل والحفاظ عليه من خلال الثقه وجودة العلاقة , كما اضافت الدراسة استخدام استراتيجيات تسويق العلاقات فى القطاع المصرفى يساعد على بناء علاقة طويله الامد مع العميل والحفاظ علية وكذلك الكالك مراعاه العملاء المخلصين , وطبقت الدراسة على 220 عميل من عملاء البنوك فى ماليزيا واستخدمت التياء الداسة تحليل الانحدار المتعدد لقياس علاقة البناء بين المتغيرات.

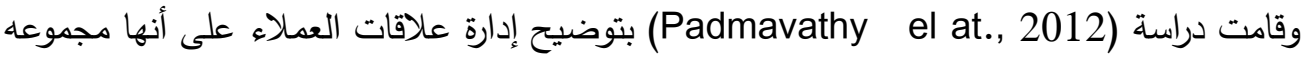
من الأنثطة الموجهه نحو العميل تدعمها الاستراتيجية التتظيمية والتكنولوجية المصممة لتحسيين

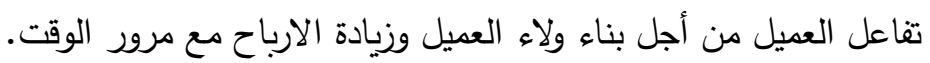
في حين توصلت دراسة (Kumar \& Soundararaja,2019 ) إلى كيفيت الحفاظ على العملاء وبناء علاقة طويله الامد بين الطرفين ولكن من منظور موظفى البنك حول العملاء , واوضحت

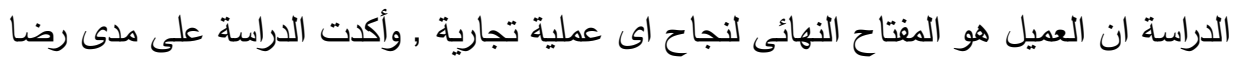

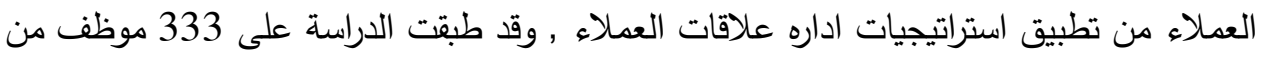
موظفى العينة ومنها 248 قطاع عام و 85 قطاع خاص .

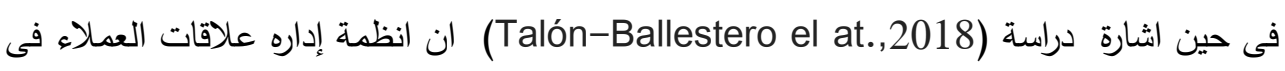

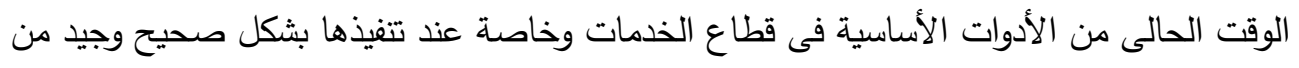

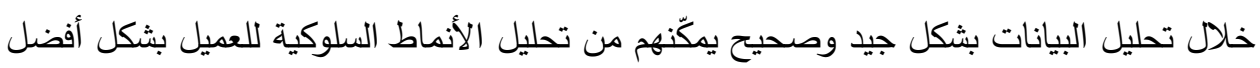
وكنلك الإحتفاظ بهم على الددى الطويل.

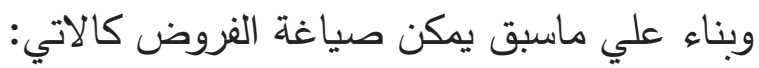

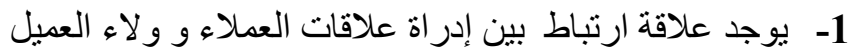
2- يوجد تأثير معنوي لإدارة علاقات العملاء علي و لاء العميل 
3- يوجد تأثثر معنوي لأبعاد إدارة علاقات العملاءعلي و لاء العميل

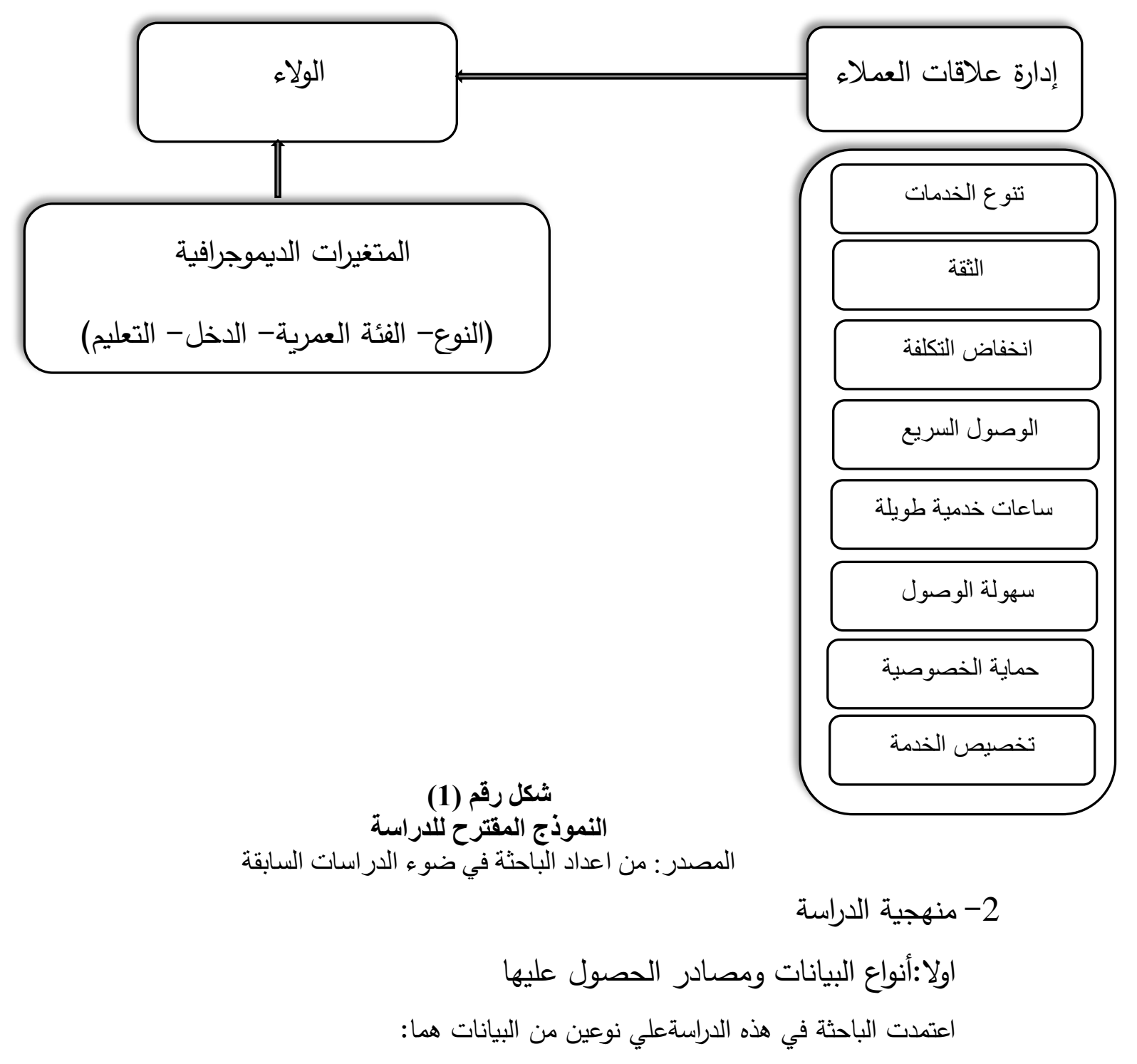


1- بيانات ثانوية: وتتمثل في البيانات التي سبق نشرها،وتم الحصول عليها من التقارير والسجلات والنشرات التي تتاولت متغيري الدراسة والموضوعات المتعلقة بهم بما يمكن الباحثة من تأصيل المفاهيم ومن اجراء الدراسة الاستطلاعية

2- بيانات اولية: تتمثل في البيانات التي تم الحصول عليها من مغردات العينة بخصوص متغيرات الدراسة بإستخدام الدراسة الميدانية علي قوائم الاستبيان أعدت وفقا لطبيعة البيانات المطلوبة وذلك في ضوء الدراسات السابقة في هذا المجال وتحليلها بما يمكن الباحثة من إختبار صحة أو خطأ فروض الداسة والتوصل الي النتائج.

\section{وقد صممت قائمة الاستقصاء للتعرف علي الأتي:}

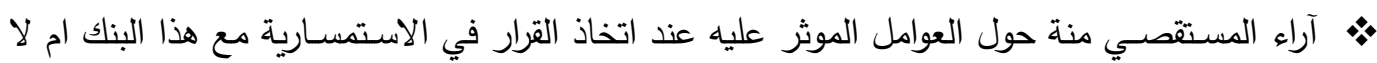
حيث طلب من المسـتقصــي منه ان يحدد التقدير المناسـب لكل عبارة من خمس تقديرات تتراوح بين موافق تماما وموافق ومحايد وغير موافق وغير موافق تماما ـ وقد تم اعطاء الاوزان 1,2,3,4,5 لكل إجابة بالترتيب علي مقياس ليكرت .

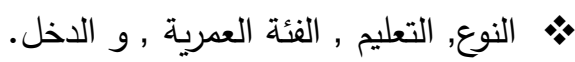

مثكلة الاراسة:

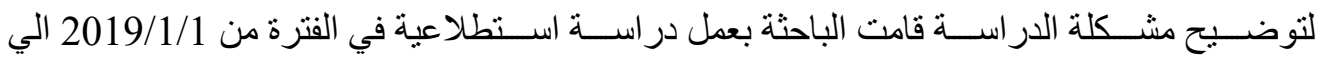

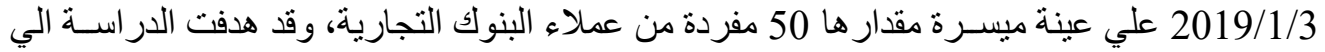

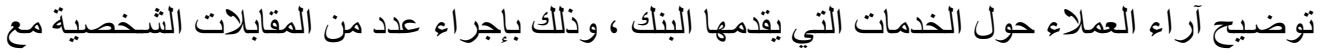

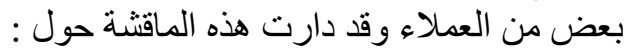
إدارة علاقات العملاء

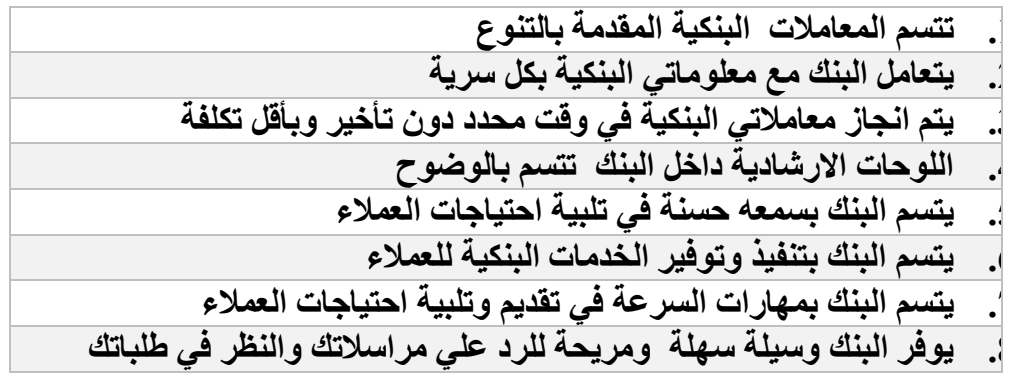




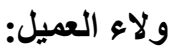

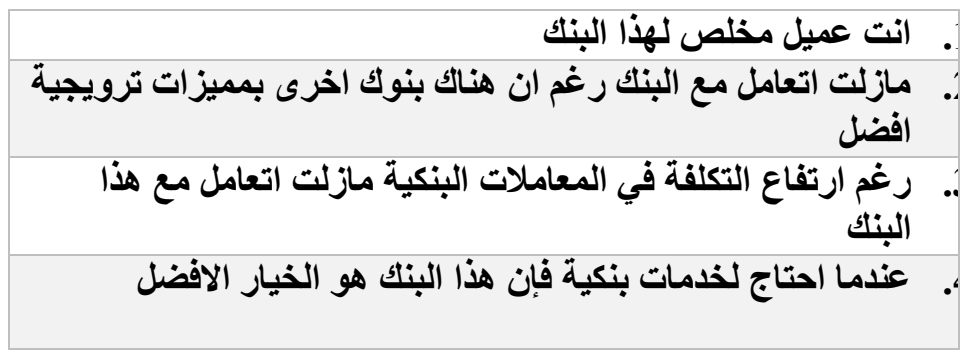

وقد توصلت نتائج الدراسة الاستطلاعية عن مجموعة من المظاهر وهي علي النحو التالي:

• ان نسبة 40\% من مفردات العينة مستعدة لتغير البنك الذي يتعاملون معه اذا لم تكن خدمة العملاء جيدة وقد يشاركون هذة التجربة السلبية مع الاصدقاء، كما أظهرت النتائج ان نسبة 60\% من مفردات العينة غير راضين

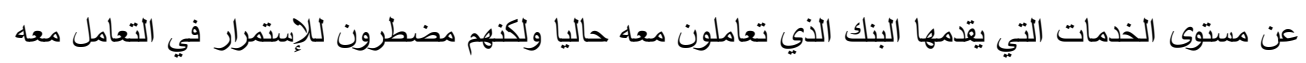
نظرا لعدم توافر الوقت لتغير البنك. • تزداد إتجاهات العملاء في سن الثباب(26-30) الي البنوك التي تقدم خدماتها عن طريق الهاتف المحمول والانترنت دون الحاجة الي زيارة البنك او استثارة احد موظفي البنك عبر الهاتف .

• ظهرت بعض الأراء حول تفضيل العملاءللبنوك التي تقوم بدور المنبه حول المعاملات المشكوك فيها .

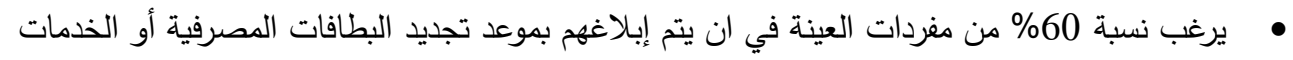

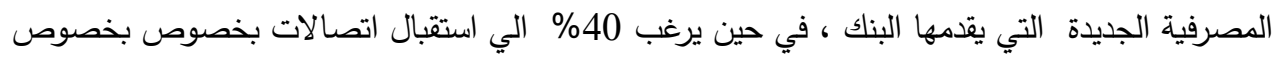
الخدمات الجديدة او العروض المقدمة. • واتفتت نسبة 67\% علي ان الالتزام بالقيم الاخلاقية والتعامل مع العملاء بإسلوب جيد وراقي يزيد من ولاء العميل مع البنك وزيادة فترة تعاملة مع البنك علي المدي البعيد. ثانيا: مجتمع وعينة الدراسة • مجتمع الاراسة: تم الاعتماد علي العينة العشوائية المنتظمة بسبب توافر شروط استخدامها وهي الشرط الاول الذي يتمثل في وجود درجة كبيرة من التجانس بيين مفردات المجتمع فيما يتعلق بالخصائص المطلوب دراستها ، والثرط الثاني عدم وجود إطار لمجتمع الدراسة. 
• جم العينة : تم تحديد حجم العينة بإستخدام برنامج يسمي Sample Size Calculator وذلك بمعلومية حجم المجتمع الذي يبلغ 100,000,000 مفردة ، وعند مستوي ثقة 95\% وحدود خطأ 5 5 \% ، وبإدخال هذة البيانات للبرنامج تم حساب حجم العينة وبلغ 400 مفردة .ويوضح الجدول

$$
\text { طريقة (1) مغردات العينة }
$$

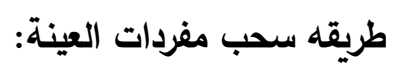

نظرا لصعوبة الحصول علي إطار لمفردات العينة ، تم الإعتماد علي الحالة الثانية للعينة المنتظمة

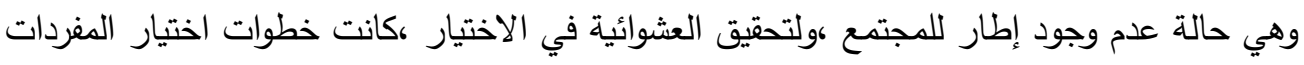
كالاتي:• تم اختيار إسبوع بطريقة عشوائية بداية من يوليو 2020

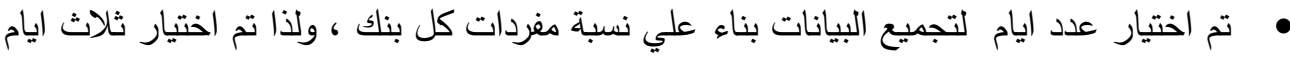

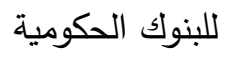

ويومين للبنوك الخاصة في السابوع بطريقة عشوائية وكانت الثنلاث ايام للبنوك الحكومية الاثثين والثلاثاء والخميس وكان اليومين للبنوك الخاصة الاحد والاربعاء

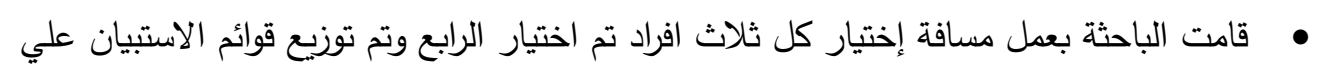
مفرات العنية حتي استكمالكفردات العينة المطلوبة

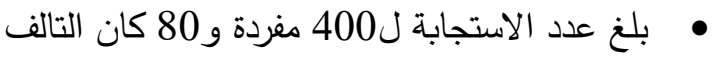




\section{جدول رقم (1)}

وصف عينة الاراسة

\begin{tabular}{|c|c|c|c|}
\hline Column N \% & Count & & \\
\hline $36.00 \%$ & 144 & أنثى & \multirow[t]{3}{*}{ النوع الن } \\
\hline $64.00 \%$ & 256 & ذكر & \\
\hline $100.00 \%$ & 400 & Total & \\
\hline $62.50 \%$ & 250 & بكالوريوس & \multirow[t]{5}{*}{ التعليم } \\
\hline $1.50 \%$ & 6 & دون ما ثانويه & \\
\hline $3.50 \%$ & 14 & دبلوم & \\
\hline $32.50 \%$ & 130 & دراسات عليا & \\
\hline $100.00 \%$ & 400 & Total & \\
\hline $7.50 \%$ & 30 & 20 إلى أقل من 25 عام & \multirow[t]{6}{*}{ الفئة العمرية } \\
\hline $31.50 \%$ & 126 & 26 إلى أقل من 30 عام & \\
\hline $26.00 \%$ & 104 & 31 إلى أقل من 35 عام & \\
\hline $21.00 \%$ & 84 & إلى أقل من 40 عام & \\
\hline $14.00 \%$ & 56 & أكثر من 40 عام & \\
\hline $100.00 \%$ & 400 & Total & \\
\hline $3.00 \%$ & 12 & 1000 من اقل & \multirow[t]{5}{*}{ الدخل } \\
\hline $7.00 \%$ & 28 & 2000 من اقل- 1000 من & \\
\hline $9.50 \%$ & 38 & 3000 من اقل - 2000 من & \\
\hline $80.50 \%$ & 322 & فأكثر جنية 3000 من & \\
\hline $100.00 \%$ & 400 & Total & \\
\hline
\end{tabular}

المصدر: إعداد الباحثة من واقع مخرجات برنامجSPSS.

• ويتضح من جدول (1) أن نسبة 36\% من إجمالي العينة من الإناث، ونسبة 64 \% من إجمالي العينة

من الذكور. 
• كما يتضح من الجدول أن التعليم مختلف من فئة دون الأخرى حيث نجد ان الاكبر نسبة هم بكالوريوس

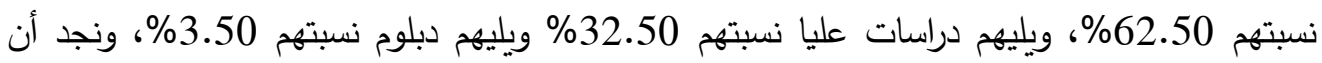
الاصغر نسبة هم ثانوية ما دون نسبتهم 1.50\%.

كما يتضح من الجدول أن النسبة الأكبر حوالى $31.50 \%$ من إجمالي العينة أعمارهم من 26 إلى أقل من 30 عام، وأن نسبة العينة من 31 إلى أقل من 35 عام 26\% بينما تتراوح نسبة من هم عمرهم من 36 إلى أقل من 40 عام هي 21\%، ومن هم أكثر من 40 عام نسبتهم 14\%. بينما النسبة الأصغر

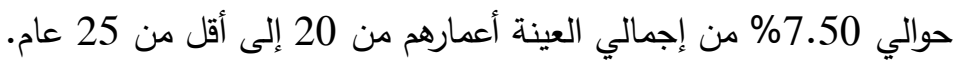

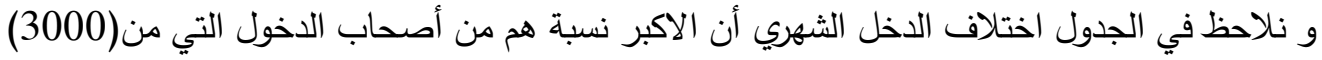

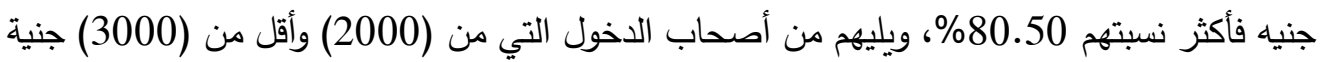
نسبتهم 9.50\%، ويليهم من أصحاب الدخول التي من (1000) وأقل من (2000) جنية نسبتهم \% \% ، ونجد أن الاصغر نسبة هم من أصحاب الدخول التي من أقل من (1000) جنية نسبتهم 3.

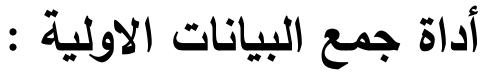

إعتمدت الباحثة في تجميع بيانات الدراسة الميدانية من مصادرها الاولية علي قايمة استبيان اعدت خصيصا لهذا الغرض في ضوء الدراسات السابقة وفي ضوه ماكثفت عنه الدراسات الاستطلاعية , وتتضمن هذه القائمة مجموعة من العبارات لقياس متغيري الدراسة ( إدارة علاقات العملاء و قيمة فترة

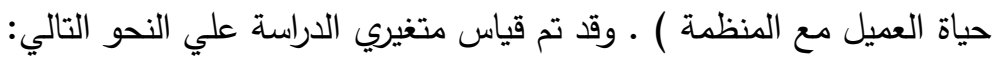
المتغير الأول: إداره علاقات العملاء تم تحديد أبعاد إدارة علاقات العملاء في تتوع الخدات - الثقه - إنخفاض التكلفة - الوصول السريع للخدمات - ساعات خدمية طويلة - سهوله الوصول للخدمات - حماية الخصوصية - تخصيص الخدمة واعتمدت الباحثة علي مقياس(2011) وتمبات فياس الوزن النسبي لكل منها باستخدام

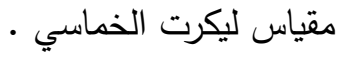
المتغير الثاني: الولاء 
تم تحديد مقياس الولاء احادي البعد علي مقياسMcDonald(1996) ; Wu \& Li (2011 وتم قياس الوزن النسبي لكل منها باستخدام مقياس ليكرت الخماسي .

\section{ثانيا: اساليب تحليل البيانات :}

اعتمدت الباحثة علي الاساليب الآتية والتي تم تنفيذها باستخدام الإصدار الثاني والعشرين من

$$
\text { البرنامج الإحصائي : }
$$

1- معامل ارتباط بيرســون : يستخدم لقياس العلاقه بين متغيرين او اكثر مع تحديد نوع العلاقة وقوتها,

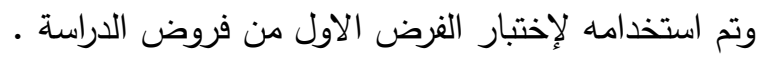

2- اسلوب الانحدار البسيط والخطي المتعدد المتدرج: لتحديد معنوية التأثير للمتغير المستقل على التابع

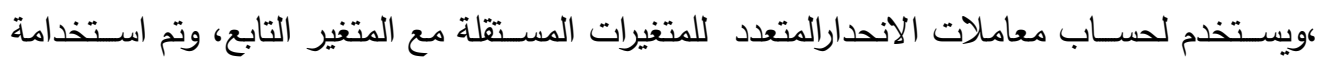

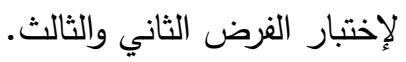

3- اختبار T-test :ويستخدم لقياس معنوية الفروق بين مجموعتين, وتم اسـتخدامه في مقياس الفروق

وفقا للنوع •

4- اختبار F-test: ويستخدم لقياس معنوية الفروق بين اكثر من مجموعتين, وتم استخدامه في قياس

الفروق وفقا للفئة العمرية والدخل والتعليم •

سابعا: نتائج الاراسة الميدانية

$$
\text { 1- - انتبار الصدق وإلثبات }
$$

تم حساب معامل الثبات ألفا كرونباخ (Alpha) لأداة الدراسة (قائمة الاستقصاء)، يعرض الجدول رقم(2) معاملى الثبات والصدق لأسئلة الاستقصاء.

وباستعراض الجدول رقم (2) يتضح أن قيم معاملات الثبات مقبولة لجميع متغيرات الدراسة،

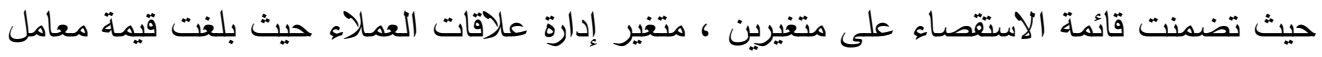

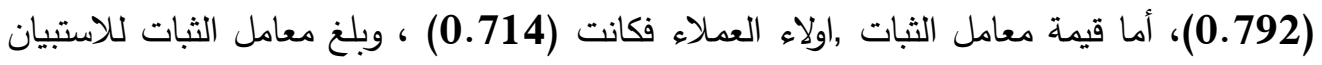
ككل 0.812، وهو ما يثير إلى درجة عالية من الاعتمادية على المقياس، وذلك باعتبار أن معامل 
ألفا الذي يتراوح ما بين 0.50 إلى 0.60 يعتبر مقبولاً، وأن معامل ألفا الذي يصل إلى 0.80 يعتبر ذا

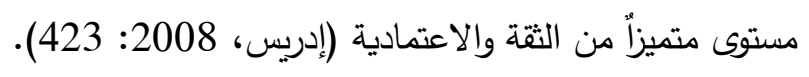

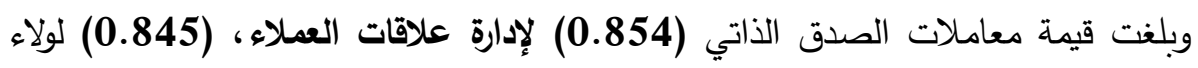

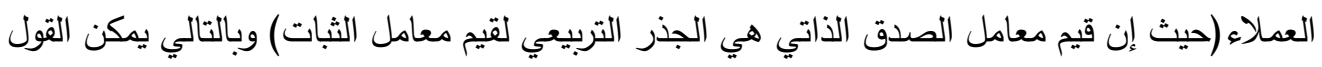
إنها معاملات ذات دلالة جيدة لتحقيق أهداف البحث ويمكن الاعتماد عليها في تعميم النتائج على لئى

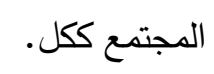
جدول رقم(2) لمعاملات الثبات و الصدق لاستمارة الاستبييان

\begin{tabular}{|c|c|c|}
\hline معامل الصدق الذاتى & $\begin{array}{l}\text { معامل الثبات } \\
\text { (Alpha)* }\end{array}$ & المتغيرات \\
\hline 0,854 & 0,729 & إدارة علاقات العملاء \\
\hline 0,845 & 0,714 & الولاء \\
\hline 0.901 & 0.812 & الاستبيان ككل \\
\hline
\end{tabular}

-2 - الأهمية النسبية لمتغيرات الاراسة من وجهة نظر المبحوثين:

أظهرت نتائج الدراسة الميدانية جدول (3) بعض المؤشرات العامة المرتبطة بقياس إدارة

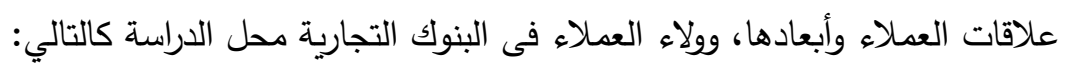

جدول رقم (3)

الأهمية النسبية لمتغيرات الاراسة (3داسة

\begin{tabular}{|c|c|c|c|c|}
\hline الأهمية النسبية & معامل الاختلاف & الانحراف المعيارى & الوسط الحسابى & المتغيرات \\
\hline 3 & 19.80 & 0.81 & 4.08 & تنوع الخذمات \\
\hline 2 & 18.22 & 0.79 & 4.33 & الثقة في الخدمات \\
\hline 7 & 28.45 & 1.03 & 3.61 & انخفاض التكلفة \\
\hline 5 & 23.55 & 0.90 & 3.82 & حماية الخصوصية \\
\hline 4 & 19.90 & 0.79 & 3.99 & تخصيص الخدمة \\
\hline 1 & 17.30 & 0.69 & 4.01 & سهولة الوصول للذدمات \\
\hline 8 & 34.11 & 1.21 & 3.54 & الوصول السريع للذدمات \\
\hline \multirow[t]{3}{*}{6} & 26.22 & 0.92 & 3.50 & ساعات خدمات طويلة \\
\hline & 16.27 & 0.63 & 3.85 & إدارة علاقات العملاء \\
\hline & 18.25 & 0.67 & 3.6788 & ولاء العملاء \\
\hline
\end{tabular}


لاختبار هذه العلاقة تم صياغة الفرض الأول من فروض الدراسة الذي ينص على أنه" لا توجد علاقة

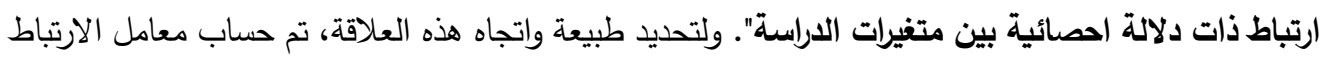

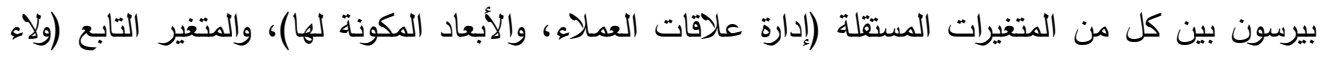

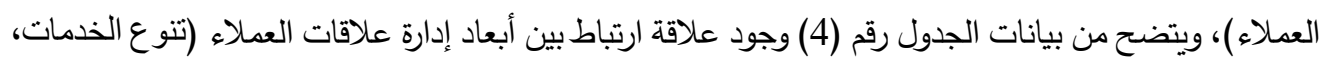

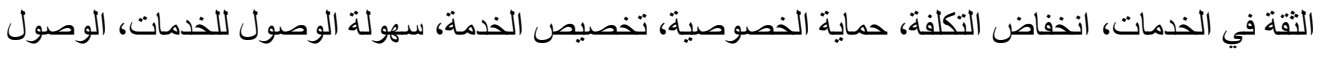

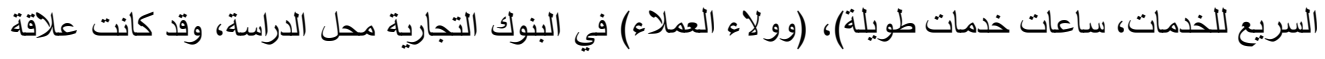

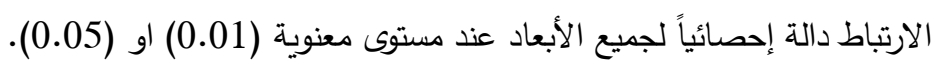

جدول رقم (4) مصفوفة ارتباط بيرسون بين إدارة علاقات العملاء وقيمة فترة حياة العميل

\begin{tabular}{|c|c|c|c|c|c|c|c|c|c|c|c|c|c|}
\hline 12 & 11 & 10 & 9 & 8 & 7 & 6 & 5 & 4 & 3 & 2 & 1 & & \\
\hline & & & & & & & & & & & 1 & الخدمات & .1 \\
\hline & & & & & & & & & & 1 & $.559^{* *}$ & الثلقة في & .2 \\
\hline & & & & & & & & & 1 & $.341^{* *}$ & $.490^{* *}$ & التففاضة & $\therefore$ \\
\hline & & & & & & & & 1 & $.515^{* *}$ & $.324^{* *}$ & $.419^{* *}$ & الخصوصية & .4 \\
\hline & & & & & & & 1 & $.494^{* *}$ & $.492^{* *}$ & $.285^{* *}$ & $.449^{* * *}$ & تخصيصة & \\
\hline & & & & & & 1 & $.505^{* *}$ & $.437^{* *}$ & $.457^{* *}$ & $.351^{* *}$ & $.509^{* *}$ & سلوصولة & .6 \\
\hline & & & & & 1 &. $\mathbf{5 5 3}^{* *}$ & $.446^{* *}$ & $.489^{* *}$ & $.648^{* *}$ & $.345^{* *}$ & $.408^{* *}$ & اللذريريع & $\therefore$ \\
\hline & & & & 1 & $.568^{* *}$ & $.410^{* *}$ & $.409^{* *}$ & $.413^{* *}$ & $.519^{* *}$ & $.235^{* *}$ & $.369^{* *}$ & شاعات & .8 \\
\hline & & & 1 & $.698^{* *}$ & $.797^{* *}$ & $.714^{* *}$ &. $\mathrm{.03}^{* *}$ & $.717^{* * *}$ & $.799^{* *}$ & $.585^{* *}$ & $.717^{* * *}$ & علالاقات & .9 \\
\hline & 1 & $.701^{* * *}$ & $.661^{* *}$ & $.562^{* *}$ & $.496^{* *}$ & $.481^{* *}$ & $.412^{* *}$ & $.445^{* *}$ & $.505^{* *}$ &. $\mathbf{3 8 0}^{* * *}$ & $.500^{* *}$ & الولاء & .10 \\
\hline
\end{tabular}
*** ** دال إحصائياً عند مستوى معنوية (0.001) ** دال إحصائياً عند مستوى معنوية (0.01) * دال إحصائياً عند

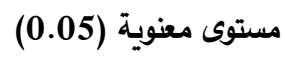

واجمالا مما سبق تستتتج الباحثة بأنه كلما زاد انخراط العملاء في إدارة علاقات العملاء، كلما صاحب التباء

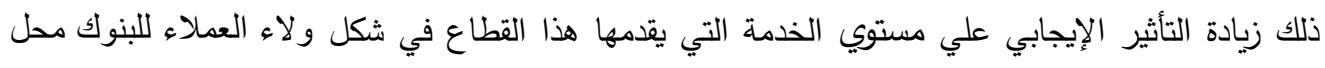


• تأثير إدارة علاقات العملاء على الولاء

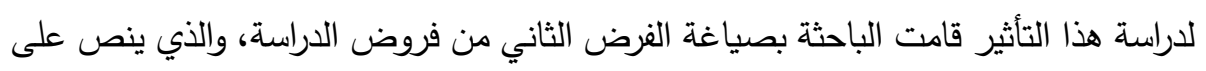

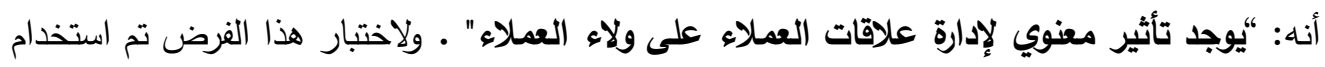

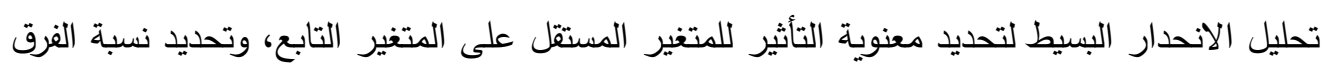

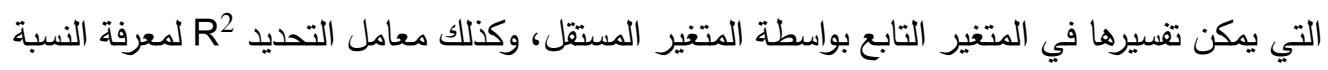

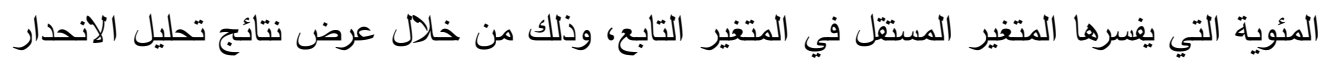

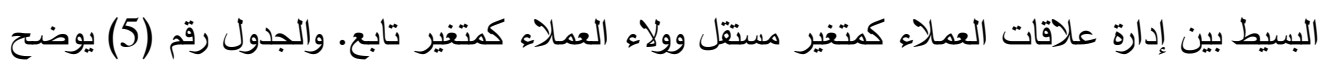

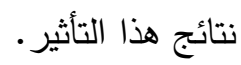

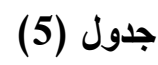

نموذج الانحدار الخطى البسيط بين إدارة علاقات العملاء على الولاء

\begin{tabular}{|c|c|c|c|c|c|c|}
\hline \multirow[t]{2}{*}{$\mathbf{R}^{2}$} & \multicolumn{3}{|c|}{ F. test } & \multirow{2}{*}{$\begin{array}{l}\text { T- test } \\
\text { القيمة }\end{array}$} & \multirow{2}{*}{ 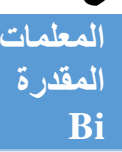 } & \multirow{2}{*}{ المستفلي } \\
\hline & مستوى & القيمة & المعنوية & & & \\
\hline \multirow[t]{2}{*}{$\% 61$} & \multirow{2}{*}{ **** 0.000} & \multirow{2}{*}{621.677} & $.000^{* * * *}$ & 6.348 & .755 & الجزء الثابت \\
\hline & & & $.000^{* * * *}$ & 24.933 & .759 & إلعملاءة علاقات \\
\hline
\end{tabular}

*** دالاً إحصائياً عذ مستوى معنوية (0.001) ** دالاً إحصائياً عند مستوى معنوية (0.01)

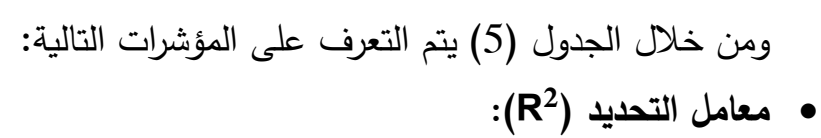

وفقاً لمعامل التحديد R مإن إن المتغير المستقل يفسر (61\%) من المتغير التابع (ولاء العملاء)،

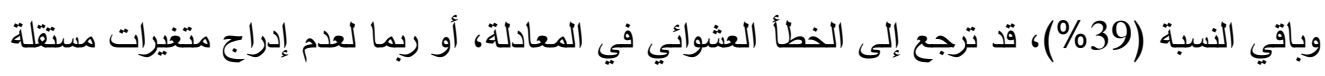

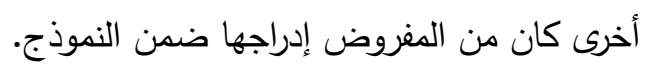

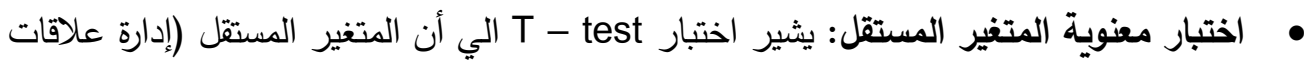

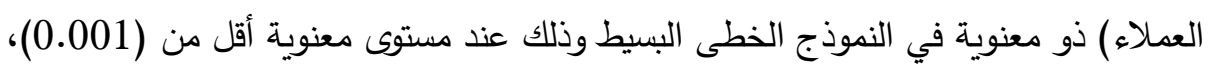

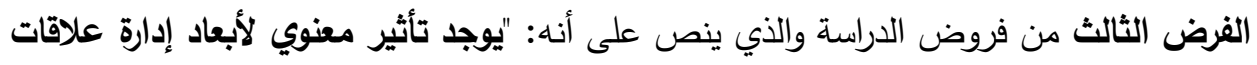

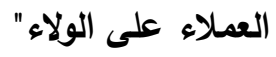


ولاختبار هذا الفرض تم استخدام أسلوب تحليل الانحدار المتعدد لتحديد نوع العلاقة بين المتغيرات المستقلة، وتحديد نسبة الفرق التي يمكن تفسيرها في المتغير التابع بواسطة المتغيرات المستقلة،

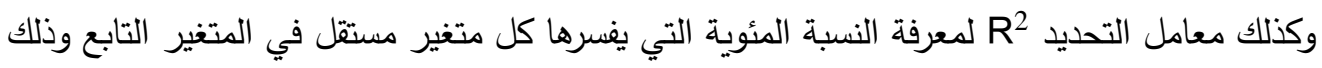

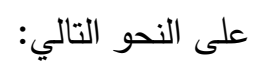

ويتم في هذا الجزء عرض نتائج تحليل الانحدار المتعدد التدريجي Stepwise بين أبعاد إدارة

علاقات العملاء (كتتغيرات مستقلة) على ولاء العملاء (المتغير التابع) وهو ما يتضح من بيانات الجدول

جدول (6) (1)

نموذج الانحدار الخطى الدتعدد التدريجي لتحديد أبعاد إدارة علاقات العملاء الأكثر تأثيراً على ولاء

العملاء

\begin{tabular}{|c|c|c|c|c|c|c|}
\hline \multirow[b]{2}{*}{$\mathbf{R}^{2}$} & \multicolumn{3}{|c|}{ F. test } & \multirow{2}{*}{$\begin{array}{l}\text { T - test } \\
\text { القيمة }\end{array}$} & \multirow{2}{*}{$\begin{array}{r}\text { المقدرة } \\
\text { Bi } \\
\text { Bi }\end{array}$} & \multirow[b]{2}{*}{ |المستيرلة } \\
\hline & 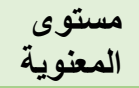 & القيمة & المعنوية & & & \\
\hline \multirow{7}{*}{$\% 46.6$} & \multirow{7}{*}{$.000^{* * *}$} & \multirow{7}{*}{57.140} & $.000 * * *$ & 4.929 & .871 & الجزء الثابت \\
\hline & & & $.000 * * *$ & 7.278 & .239 & 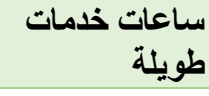 \\
\hline & & & $.002 * *$ & 3.172 & .134 & تنوع الخدمات \\
\hline & & & $.003 * *$ & 3.013 & .135 & ل اللذهولة الوصول \\
\hline & & & $.024^{*}$ & 2.271 & .073 & انخفاض التكلقة \\
\hline & & & $.033 *$ & 2.137 & .082 & 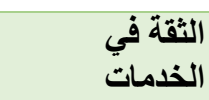 \\
\hline & & & $.041 *$ & 2.053 & .070 & الخصوصية \\
\hline \multicolumn{7}{|c|}{ 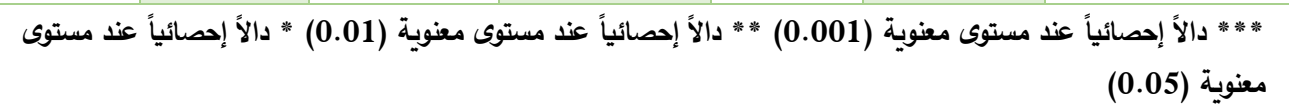 } \\
\hline
\end{tabular}


وفقاً لمعامل التحديد R2 فإن المتغيرات المستقلة تفر (46.6\%) من المتغير التابع (ولاء

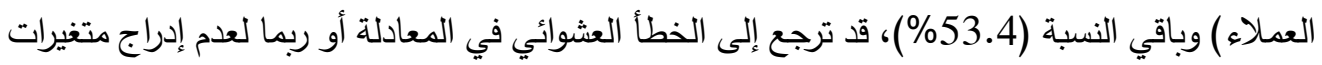

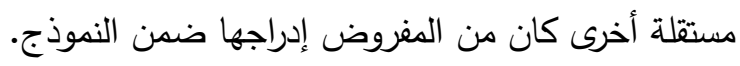
اختبار معنوية كل متغير مستقل على حدة:

باختبار T - test نجد أن المتغيرات المستقلة ذات المعنوية في النموذج الخطى المتعدد هي (ساعات خذمات طويلة، تنوع الخدمات، سهولة الوصول للخدمات، انخفاض التكلفة، الثقة في الخدمات، حماية الخصوصية) وذلك عند مستوى معنوية أقل من (0.001)، وقد خرج من النموذج بعدين (تخصيص الخدمة، الوصول السريع للخدمات) حيث لم تثبت معنويتهما. كما اتضح من قيم اختبار (T-test) أن أقوى أبعاد إدارة علاقات العملاء تأثيراً على ولاء لاء التهات

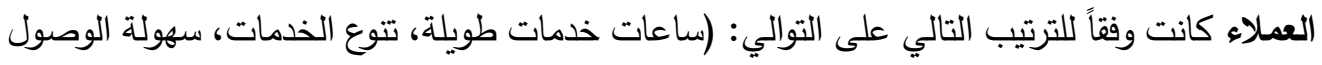

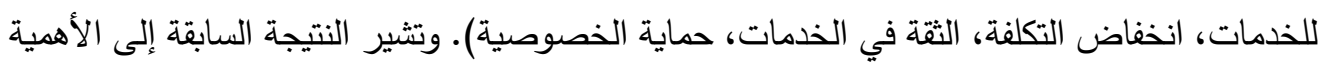

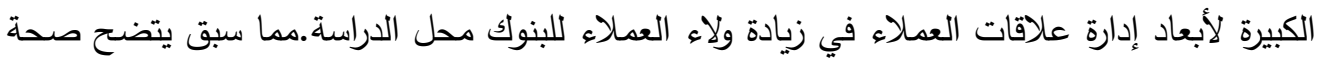
الفرض الثالث جزئياً، أي أنه يوجد تأثير معنوي لأبعاد إدارة علاقات العملاء على ولاء العاء العملاء. ثالثا : مناقشة الاراسة الميدانية :

اوضحت : نتائج الدراسة الاحصائية وجود علاقة إرتباط معنوي بين ادارة علاقات العملاء

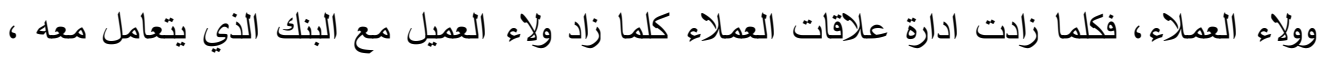

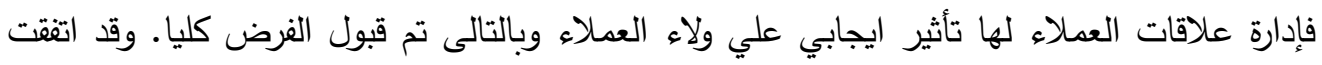

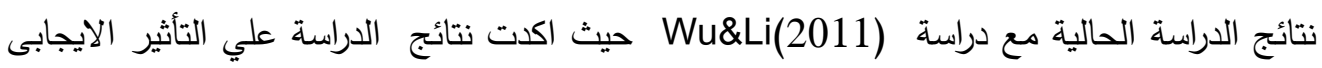

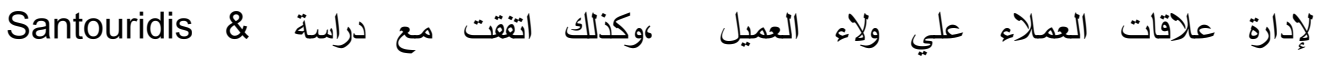

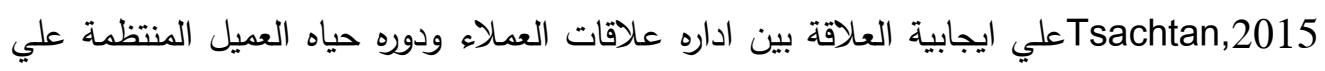

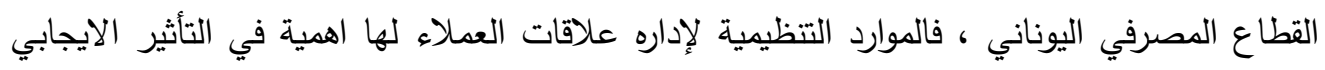
الملحوظ علي دوره حياه العميل وولائه والحفاظ عليه. واوضحت النتائج انه توجد فروق معنوية بين آراء العملاء في البنوك التجارية محل الدراسة نحو إدراكهم

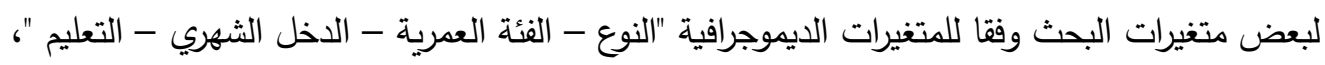


فتزداد اتجاهات العملاء في سن 30-26 الي البنوك التي تقدم خذماتها عن طريق الهاتق المحمول والانترنت دون الحاجه الي زيارة البنك او استثارة احد الموظفين عبر الهاتف، اتنقت مع دراسة Yang,Hu,\& Zhang,2007 ان السمعه والثقه تلعب دولا هاما في تغير اتجاه العيل نحو الخدمة

الافضل.

اوضحت نتائج الدراسة وجود علاقة ايجابية بين اراء العملاء بالبنوك التجارية فيما يتعلق

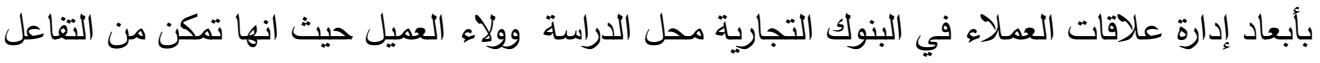

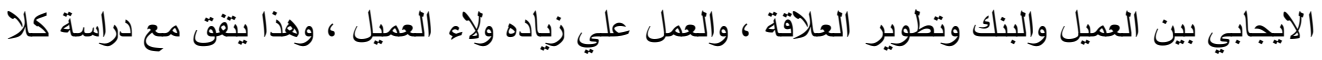
من (Reinartz el at.,2004 \&Mithas el at.,2005) حيث انها تتص علي كلما زاد تطوير لادارة العلاقات يساعد على رضا العميل ومعرفته ، كما ان المعرفة المرجوة من ادارة علاقات العملاء

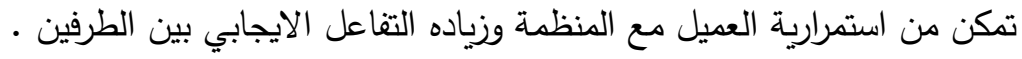
رابعا: توصيات الدراسة:

في ضوء ما اسفرت عنه نتائج الدراسة، تقدم الباحثة مجموعة من التوصيات التي ترتكز في

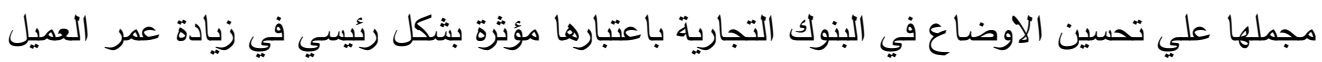
في البناك. وتتمثل هذه التوصيات فيما يلي:

1- عمل استبيان عام من جميع العملاء بالبنوك التجارية ككل لأخذ آرائهم ومعرفة وجهات نظرهم في

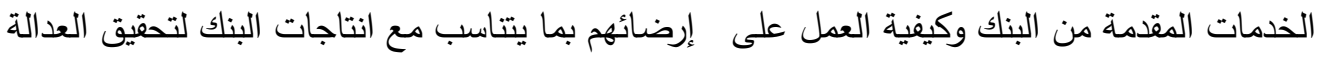
والمساواة فيما بينهم. 2- ضرورة سعى في الادارة العليا والمتوسطة بالبنوك التجارية إلى اتخاذ كافة الإجراءات الازمة والكفيلة بزيادة ولاء العملاء

3- الاهتمام بخدمة العملاء وجعلها من أهم اهتمامات جميع العاملين وليس موظفي الاقسام الامامية فقط.

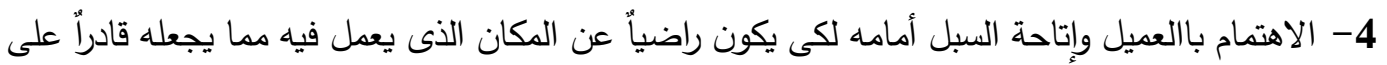
تقييم الخدمة على أكمل وجه وبالتالي سوف يعود على البنوك بالسمعة الحسنه. 


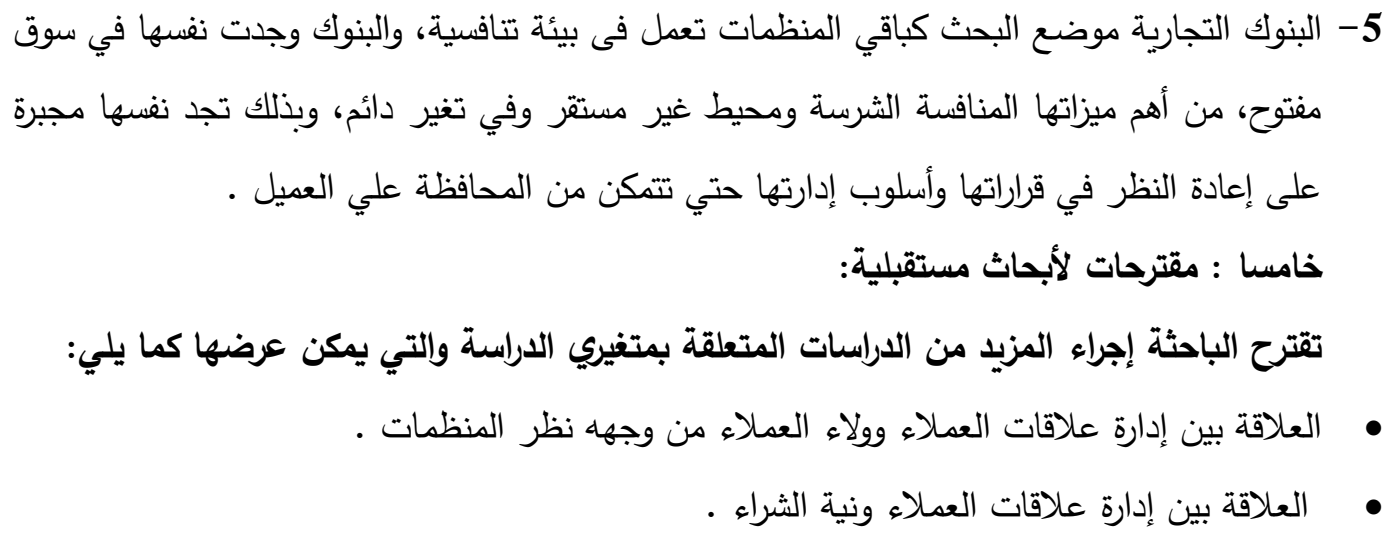

- Becker, J. U., Greve, G., \& Albers, S. (2009). The impact of technological and organizational implementation of CRM on customer acquisition, maintenance, and retention. International Journal of Research in Marketing, 26(3), 207-215.

- Berry, L. L., Bennett, D. R., \& Brown, C. W. (1989). Service quality: A profit strategy for financial institutions. Irwin Professional Pub.

- Bose, R. (2002). Customer relationship management: key components for IT success. Industrial management \& Data systems, 102(2), 89-97.

- Da Silveira, G., Borenstein, D., \& Fogliatto, F. S. (2001). Mass customization: Literature review and research directions. International journal of production economics, 72(1), $1-13$. 
- Elfving, J., \& Lemoine, K. (2012). Exploring the concept of Customer Relationship Management: emphasizing social.

- Er, W. K. (2020). A Study on Relationship Between Customer Relationship Management (CRM) and Customer Satisfaction on Taobao Website in Johor Bahru. Journal of Arts \& Social Sciences, 3(2), 1-14.

- Ghobadian, A., Speller, S., \& Jones, M. (1994). Service quality: concepts and models. International journal of quality \& reliability management, 11(9), 43-66.

- Grant, R. M. (1999). The resource-based theory of competitive advantage: implications for strategy formulation. In Knowledge and strategy (pp. 3-23).

- Johnson, D., \& Grayson, K. (2005). Cognitive and affective trust in service relationships. Journal of Business research, 58(4), 500507.

- Keeney, R. L. (1999). The value of Internet commerce to the customer. Management science, 45(4), 533-542.

- Kim, M. K., Park, M. C., \& Jeong, D. H. (2004). The effects of customer satisfaction and switching barrier on customer loyalty in Korean mobile telecommunication services._Telecommunications policy, 28(2), 145-159.

- Kim, W. G., \& Cha, Y. (2002). Antecedents and consequences of relationship quality in hotel industry. International Journal of Hospitality Management, 21(4), 321-338.

- Kumar, A. S., \& Soundararaja, K. V. (2019). Customer Relationship Management in Banking Sector: A Study on Bank Employees 
Perception about Customers in Tirunelveli District. IJELLH (International Journal of English Language, Literature in Humanities), 7(2), 16-16.

- McDonald, M. A. (1996). Service quality and customer lifetime value in professional sport franchises.

- Mithas, S., Krishnan, M. S., \& Fornell, C. (2005). Why do customer relationship management applications affect customer satisfaction?. Journal of Marketing, 69(4), 201-209.

- Moloo, R. K., Kissoon, M., \& Cootthen, S. (2010). A lightweight mobile banking solution easily integrateable with existing banking system. In Annual International Conference on Infocomm Technologies in Competitive Strategies (pp. 42-49).

- Nayyar, P. R. (1990). Information asymmetries: A source of competitive advantage for diversified service firms. Strategic Management Journal, 11(7), 513-519.

- Ngambi, M. T., \& Ndifor, P. S. (2015). Customer relationship management and firm performance: Revisiting the case of the Camccul Microfinance Institutions. International Journal of Information Technology and Business Management, 38(1), 1221.

- O'Connell, J. F., \& Connolly, D. (2017). The strategic evolution of Aer Lingus from a full-service airline to a low-cost carrier and finally positioning itself into a value hybrid airline. Tourism Economics, 23(6), 1296-1320. 
- Oliver, R. L., \& Burke, R. R. (1999). Expectation processes in satisfaction formation: A field study. Journal of Service Research, 1(3), 196-214.

- Oly Ndubisi, N., Kok Wah, C., \& Ndubisi, G. C. (2007). Suppliercustomer relationship management and customer loyalty: The banking industry perspective. Journal of Enterprise Information Management, 20(2), 222-236.

- Padmavathy, C., Balaji, M. S., \& Sivakumar, V. J. (2012). Measuring effectiveness of customer relationship management in Indian retail banks. International Journal of Bank Marketing, 30(4), 246-266.

- Porter, M. E. (1986). Changing patterns of international competition. California management review, 28(2), 9-40.

- Reichheld, F. F., \& Sasser, J. W. (1990). Zero defections: Quality comes to services. Harvard business review, 68(5), 105-111.

- Reinartz, W., Krafft, M., \& Hoyer, W. D. (2004). The customer relationship management process: Its measurement and impact on performance. Journal of marketing research, 41(3), 293-305.

- Roth, S., Woratschek, H., \& Pastowski, S. (2006). Negotiating prices for customized services. Journal of Service Research, 8(4), 316-329.

- Roznowski, J. L. (2003). A content analysis of mass media stories surrounding the consumer privacy issue 1990-2001. Journal of interactive marketing, $17(2), 52-69$.

- Rutecka, J., \& Bednarz, J. (2017). GENERATION Y'S INTEREST IN INTERNET BANKING SERVICES-THE 


\section{RESULTS OF EMPIRICAL STUDIES. Contemporary}

Economy, 8(2), 1-16.

- Santouridis, I., \& Tsachtani, E. (2015). Investigating the impact of CRM resources on CRM processes: a customer life-cycle based approach in the case of a Greek bank. Procedia Economics and Finance, 19, 304-313.

- Saunders, M., Lewis, P., \& Thornhill, A. (2009). Research methods for business students. Pearson education.

- Shokohyar, S., Tavalaee, R., \& Karamatnia, K. (2017). Identifying effective indicators in the assessment of organizational readiness for accepting social CRM. International Journal of Information, Business and Management, 9(4), 209.

- Sorescu, A. B., \& Spanjol, J. (2008). Innovation's effect on firm value and risk: Insights from consumer packaged goods. Journal of Marketing, 72(2), 114-132.

- Swift, R. S. (2001). Accelerating customer relationships: Using CRM and relationship technologies. Prentice Hall Professional.

- Talón-Ballestero, P., González-Serrano, L., Soguero-Ruiz, C., Muñoz-Romero, S., \& Rojo-Álvarez, J. L. (2018). Using big data from customer relationship management information systems to determine the client profile in the hotel sector. Tourism Management, 68, 187-197.

- Turulja, L., \& Činjarević, M. (2021). Connecting the Dots Between E-CRM and Customer Loyalty: Mediating Role of Perceived Value and Customer Support. In Handbook of Research on Technology 
Applications for Effective Customer Engagement (pp. 123-140). IGI Global.

- Wu, S. I., \& Li, P. C. (2011). The relationships between CRM, $\mathrm{RQ}$, and CLV based on different hotel preferences. International Journal of Hospitality Management, 30(2), 262-271.

- Yang, J., Hu, X., \& Zhang, H. (2007). Effects of a reputation feedback system on an online consumer-to-consumer auction market. Decision Support Systems, 44(1), 93-105. 